\begin{tabular}{|c|c|c|}
\hline & $K$ & $\begin{array}{l}\text { Salt hydrolyzed in } \\
\text { per cent. }\end{array}$ \\
\hline 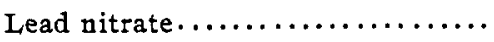 & 0.00244 & 0.096 \\
\hline Manganous chloride $\ldots \ldots \ldots \ldots$ & 0.00095 & 0.035 \\
\hline 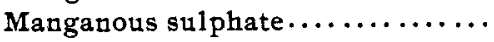 & 0.00052 & 0.020 \\
\hline Ferrous sulphate..$\ldots \ldots \ldots \ldots \ldots$ & 0.00085 & 0.033 \\
\hline Ferrous ammonium sulphate ..... & 0.00068 & 0.026 \\
\hline Zinc sulphate $\ldots \ldots \ldots \ldots \ldots \ldots \ldots$ & 0.00040 & 0.016 \\
\hline 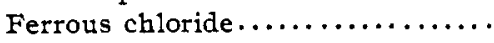 & 0.00164 & 0.063 \\
\hline Ferrous bromide $(0.54 N) \ldots \ldots \ldots$ & 0.00300 & 0.109 \\
\hline Ferrous iodide................ & 0.00198 & 0.078 \\
\hline Potassium aluminum sulphate, $\frac{N}{4}$ & 0.01835 & $\mathrm{I} .440$ \\
\hline Cadmium chloride $0.94 N \ldots \ldots \ldots$. & 0.01000 & 2.080 \\
\hline
\end{tabular}

The amount of hydrolysis is small in all cases except those of the alum and cadmium chloride.

My thanks are due to Mr. S. R. Macy for much assistance in the experimental work of the above.

NoRTHWESTERN UNIVERSITY,

CHICAGO.

\title{
DETERMINATION OF IRON OXIDE AND ALUMINA IN PHOSPHATE ROCK BY THE AMMONIUM ACETATE METHOD.
}

\author{
By Thomas S. GladdiNg. \\ Received June 30,2896 .
}

$7 \mathrm{HE}$ oldest method of separating alumina and iron phosphates from lime phosphate is, probably, the ammonium acetate method. This has been severely criticised, and just at present seems to be under condemnation. The following investigation has convinced the writer that, when properly carried out, not only does the method give an accurate separation of iron and alumina from lime phosphate, but also gives a neutral phosphate of uniform composition from which the iron oxide and alumina present may be accurately estimated.

In brief, the method used is this. If a weakly acid solution of phosphates of iron and alumina together with a large amount of calcium phosphate be slowly poured into a strong solution of ammonium acetate made acid with acetic acid, the iron and alumina are precipitated as phosphates, upon digestion for a short time at a gentle heat. This precipitate, however, con- 
tains more or less calcium phosphate, which is removed by several reprecipitations. I shall demonstrate by experiment:

First, That upon continued reprecipitations of iron and alumina as phosphates in this manner, there is no appreciable diminution of the quantity of either finally obtained, provided there always be a large excess of phosphoric acid present.

A standard solution was made by dissolving twenty grams of ammonia alum (C. P.) in distilled water. This was slightly acidified with hydrochloric acid, in order to prevent the alumina from separating on standing, and diluted to one liter. This solution, upon being standardized, was found to contain the theoretical amount of alumina, that is,

$$
\text { Ten cc. }=0.0225 \text { grams } \mathrm{Al}_{2} \mathrm{O}_{3} \text {. }
$$

One precipitation, in the manner described above, of the alumina in ten $c c$. gave

$\begin{array}{ccc} & \mathrm{Al}_{2} \mathrm{O}_{3}, \mathrm{P}_{2} \mathrm{O}_{5}, \text { found. } & \mathrm{A}_{2} \mathrm{O}_{3} . \\ \mathrm{I} & 0.0545 & 0.0228 \\ 2 & 0.0549 & 0.0229 \\ 3 & 0.0546 & 0.0228 \\ 4 & 0.0540 & 0.0226 \\ 5 & 0.0545 & 0.0228\end{array}$

Three successive precipitations, in which one gram of ammonium phosphate was added before each precipitation, gave

$\begin{array}{ccc} & \mathrm{Al}_{2} \mathrm{O}_{3} \cdot \mathrm{P}_{2} \mathrm{O}_{5} . & \mathrm{Al}_{2} \mathrm{O}_{3} \\ \mathrm{I} & 0.0550 & 0.0230 \\ 2 & 0.0547 & 0.0229 \\ 3 & 0.0544 & 0.0227\end{array}$

Five successive precipitations were also tried under the same conditions, with the following results :

$\begin{array}{cc}\mathrm{Al}_{2} \mathrm{O}_{3} \cdot \mathrm{P}_{2} \mathrm{O}_{5} . & \mathrm{Al}_{2} \mathrm{O}_{3} \\ 0.0536 & 0.0224 \\ 0.0530 & 0.0222\end{array}$

When, however, the excess of phosphoric acid was omitted before the reprecipitations, there was a loss of alumina.

An iron solution was made by dissolving C. P. iron wire in hydrochloric acid and oxidizing it with nitric acid. When carefully standardized it was found that

$$
\text { Ten cc. }=0.0296 \mathrm{Fe}_{2} \mathrm{O}_{3} \text {. }
$$


Three successive precipitations, adding one gram ammonium phosphate before each, gave

$\begin{array}{ccc} & \mathrm{Fe}_{2} \mathrm{O}_{3} \cdot \mathrm{P}_{2} \mathrm{O}_{5} . & \mathrm{Fe}_{2} \mathrm{O}_{3} \\ \mathrm{I} & 0.0545 & 0.0289 \\ 2 & 0.055^{\circ} & 0.0291 \\ 3 & 0.0548 & 0.0290\end{array}$

Five successive precipitations, in the same way, gave

$\begin{array}{ccc} & \mathrm{Fe}_{2} \mathrm{O}_{3}, \mathrm{P}_{2} \mathrm{O}_{5} . & \mathrm{Fe}_{2} \mathrm{O}_{3} . \\ \mathrm{I} & 0.0550 & 0.029 \mathrm{I} \\ 2 & 0.0560 & 0.0297\end{array}$

Second. That upon three successive precipitations in the presence of a large amount of calcium phosphate, as is the case in the analysis of rock phosphate, the precipitate of the phosphates of iron and alumina is sufficiently pure to be taken as such. Of the standard solutions, five cc. of each would together give a precipitate of combined phosphates about equal to that usually found in one gram of phosphate rock. The mixture so analyzed was made up as follows:

Five cc. alumina solution $=0.012_{25} \mathrm{Al}_{2} \mathrm{O}_{3}$.

Five cc. iron solution $=0.01480 \mathrm{Fe}_{2} \mathrm{O}_{3}$.

0.7000 grams calcium phosphate.

This was given three precipitations, the excess of phosphoric acid being supplied before the second and third precipitations.

$\begin{array}{cccc} & \text { Phosphates obtained. } & \mathrm{Al}_{2} \mathrm{O}_{8} \text { obtained. } & \mathrm{Fe}_{2} \mathrm{O}_{8} \text { obtained. } \\ 2 & 0.0552 & 0.01 \mathrm{I}_{5} & 0.0 \mathrm{I}_{4} 6 \\ 3 & 0.0540 & 0.0110 & 0.0146 \\ 4 & 0.0537 & 0.0109 & 0.0146 \\ 4 & 0.0536 & 0.0109 & 0.0146\end{array}$

The iron oxide was determined by volumetric method in the ignited precipitate and the alumina by subsequent calculation.

In addition twenty $\mathrm{cc}$. alumina solution containing $0.045^{\circ}$ grams $\mathrm{Al}_{2} \mathrm{O}_{3}$, together with 0.700 grams calcium phosphate, were given three successive precipitations in the same way with the following results :

$\begin{array}{ccc} & \mathrm{Al}_{2} \mathrm{O}_{3} \cdot \mathrm{P}_{2} \mathrm{O}_{5} \text { obtained. } & \mathrm{Al}_{2} \mathrm{O}_{3} \text { obtained. } \\ \text { Grams. } & 0.0 m s . \\ \text { I } & 0.1092 & 0.0456 \\ 2 & 0.1074 & 0.0449\end{array}$

In order to prove that the aluminum phosphate precipitated was the normal phosphate, the ignited precipitates were fused, and the phosphoric acid in them estimated. 


$\begin{array}{ccccc} & \mathrm{Al}_{2} \mathrm{O}_{3} \cdot \mathrm{P}_{2} \mathrm{O}_{5} . & \mathrm{P}_{2} \mathrm{O}_{5} \text { obtained. } & \mathrm{Al}_{2} \mathrm{O}_{3} \text { by diff. } & \mathrm{Al}_{2} \mathrm{O}_{3} \text { by calc. } \\ \mathrm{I} & 0.0538 & 0.03 \mathrm{I} 3 & 0.0225 & 0.0225 \\ 2 & 0.0533 & 0.03 \mathrm{I} 2 & 0.022 \mathrm{I} & 0.0223\end{array}$

The phosphate of alumina is multiplied by the factor 0.4 I 8 to obtain the alumina.

Therefore, in determining iron oxide and alumina in phosphate rocks proceed as follows:

Four grams of the finely ground sample, previously freed by a magnet from any metallic iron derived from the iron mortar used in grinding the sample, are digested for half an hour, at a temperature just below the boiling-point, with about thirty cc. dilute hydrochloric acid ( $I-r)$. This will prevent the solution of any pyrites if present. Filter and wash thoroughly into a 200 cc. flask, add a little nitric acid, and boil to oxidize the iron, cool, and fill to mark with water. Take two portions, fifty cc. $=$ one gram, twenty-five cc. $=$ one-half gram, and proceed with each as follows :

Almost neutralize the solutions with strong ammonium hydroxide until the precipitate formed dissolves with difficulty, and thoroughly cool by placing the beaker in a dish of cold water. The neutralization is then completed by carefully adding dilute ammonium hydroxide until the precipitate remains permanent, then just dissolve by adding dilute hydrochloric acid, drop by drop, stirring well. Have ready in another beaker a mixture of fifteen cc. of a strong solution of ammonium acetate (made by neutralizing thirty per cent. acetic acid with strong ammonium hydroxide) and five cc. of acetic acid. Carefully pour the cold faintly acid solution of phosphates in a fine stream into this mixture, stirring all the while. Digest at $60^{\circ} \mathrm{C}$. from one-half hour to one hour, until the supernatant liquid is clear and the flocculent precipitate is well settled to the bottom.

Filter and wash the precipitate once with a ten per cent. ammonium acetate solution, merely rinsing out the beaker in which the precipitation was made. Dissolve the precipitate from the paper into the same beaker with a few cubic centimeters of hot dilute hydrochloric acid $(x-4)$. Use as little acid as possible in order to keep the bulk of the solution small. Add one gram of ammonium phosphate, neutralize with ammonium 
hydroxide and add hydrochloric acid until the precipitate just dissolves as before and pour into a mixture of fifteen cc. ammonium acetate solution and five cc. acetic acid. Digest at $60^{\circ} \mathrm{C}$. for one-half to one hour and filter, and wash once with the ten per cent. ammonium acetate solution. Redissolve and repeat the precipitation, being careful to again add one gram of ammonium phosphate to the solution, in order that there be a sufficient excess of phosphorus pentoxide to precipitate all the alumina as a neutral phosphate. Wash the precipitate three times with dilute ammonium acetate solution.

Take the filter, while wet, from the funnel and ignite in a tared platinum capsule, using a very low flame until the filter paper is thoroughly charred. The heat is increased gradually until the paper is completely consumed, and finally the blast lamp is used for a minute. Weigh as combined phosphates of iron and alumina. The iron is determined volumetrically in the solution of the weighed precipitates. The iron oxide present in the rock is also determined separately by volumetric process, preferably the bichromate method, in a solution of five grams of the rock in dilute hydrochloric acid ( $I-I$ ), reducing all iron to protoxide and titrating with bichromate.

The ignited precipitate from one of the duplicate precipitations may, if desired, be dissolved and subjected to a fourth precipitation and the filtrate tested for lime by adding ammonium oxalate and heating. My thanks are due to our assistant, Thomas Brown, Jr., for valuable aid in the above analytical determinations.

LABORATORY OF STILLWELL \& GLADDING, NEW YORK CITY.

\title{
A NEW METHOD FOR THE ESTIMATION OF IRON OXIDE AND ALUMINA IN PHOSPHATE ROCK.
}

\author{
By Thomas s, GladdiNG. \\ Received June $3^{\circ}$, r\&gs.
}

$T_{\mathrm{HE}}^{\mathrm{m} \text { method for the separation of alumina from phosphate }}$ of lime by three successive precipitations with ammonium acetate is tedious, though accurate if proper precautions be taken, as shown in the preceding paper on this subject.

The following modification suggested itself as saving both 